\title{
Pressure Drop of Water Flow Across a Micro-Pin-Fin Array Part 2: Adiabatic Liquid-Vapor Two-Phase Flow
}

\author{
Jonathan Mita, Weilin Qu* \\ Department of Mechanical Engineering \\ University of Hawaii at Manoa \\ Honolulu, Hawaii 96822
}

\begin{abstract}
This is part two of a two-part study that investigates water pressure drop across a staggered array of circular micro-pin-fins. This paper reports results of adiabatic liquid-vapor two-phase flow, and part one isothermal liquid single-phase flow. The micro-pin-fins are 180 microns in diameter, 683 microns in height, and 399 microns in both longitudinal and transverse pitches. Seven maximum mass velocities from 171 to $491 \mathrm{~kg} / \mathrm{m}^{2} \mathrm{~s}$, and sixteen vapor qualities for each maximum mass velocity were tested. Two-phase pressure drop across the micro-pin-fin array was measured, and two-phase friction multiplier and Martinelli parameter calculated. It was revealed that a unique functional relationship exists between the two-phase friction multiplier and Martinelli parameter, which proved that the generalized procedure developed by Lockhart and Martinelli could be applied to describe two-phase pressure drop across the micropin-fin array. The existing Martinelli-Chisholm type correlations for staggered micro-pin-fin arrays and tube banks were unable to predict the data, and a new correlation was developed.
\end{abstract}

Keywords: micro-pin-fins, heat sink, liquid cooling, two-phase, pressure drop, two-phase friction multiplier

* Author to whom correspondence should be addressed, Tel: (808) 956-6332, Fax (808) 9562373, E-mail: qu@hawaii.edu 


\section{Nomenclature:}

\begin{tabular}{|c|c|}
\hline$A_{\min }$ & Minimum transverse flow area \\
\hline$A_{\max }$ & Maximum transverse flow area \\
\hline C & $C$ factor in Martinelli-Chisholm type correlations \\
\hline$D$ & Diameter of a circular pin-fin \\
\hline$f$ & Friction factor \\
\hline$G_{\max }$ & Maximum mass velocity \\
\hline$G_{\min }$ & Minimum mass velocity \\
\hline$G_{p 1}, G_{p 2}$ & Mass velocity in plenums \\
\hline$G_{t s}$ & Mass velocity in test section inlet and outlet \\
\hline$h$ & Enthalpy \\
\hline$h_{v g, \text { in }}$ & Enthalpy of the liquid water upstream of the vapor generator \\
\hline$H$ & Height of a pin-fin \\
\hline$K_{c 1}, K_{c 2}$ & Contraction loss coefficient \\
\hline$K_{e 1}, K_{e 2}$ & Expansion recovery coefficient \\
\hline$\dot{m}$ & Mass flow rate \\
\hline$M A E$ & Mean absolute error \\
\hline$N_{L}$ & Total number of pin-fin rows in longitudinal direction \\
\hline$P$ & Pressure \\
\hline$P_{W}$ & Heating power input \\
\hline$\Delta P_{c 1}, \Delta P_{c 2}$ & Contraction pressure loss \\
\hline$\Delta P_{e 1}, \Delta P_{e 2}$ & Expansion pressure recovery \\
\hline$\Delta P_{t p}$ & Pressure drop across test section \\
\hline$\Delta P_{t p, f i n}$ & Pressure drop across micro-pin-fin array \\
\hline$Q_{\text {loss }}$ & Heat loss \\
\hline $\operatorname{Re}$ & Reynolds number \\
\hline$S$ & Side length of a square pin-fin \\
\hline$S_{L}$ & Longitudinal pitch \\
\hline$S_{T}$ & Transverse pitch \\
\hline$T$ & Temperature \\
\hline$v$ & Specific volume \\
\hline
\end{tabular}




$\begin{array}{ll}W & \text { Width of test section top platform area } \\ W_{\text {wall }} & \text { Thickness of thin side walls along test section edges } \\ X & \text { Vapor quality } \\ X_{e} & \text { Thermodynamic equilibrium quality } \\ X & \text { Martinelli parameter } \\ Z & \text { Stream-wise distance }\end{array}$

\section{Greek}

$\begin{array}{ll}\alpha & \text { Void fraction } \\ \phi & \text { Two-phase friction multiplier } \\ \mu & \text { Dynamic viscosity }\end{array}$

\section{Subscripts}

$\begin{array}{ll}\text { A } & \text { Accelerational } \\ \text { exp } & \text { Experimental } \\ f & \text { Liquid } \\ f g & \text { Difference between liquid and vapor } \\ f i n & \text { Pin-fin array } \\ F & \text { Frictional } \\ g & \text { Vapor } \\ i & \text { Streamwise segment } \\ \text { ibd0 } & \text { Upstream boundary of segment i } \\ \text { idb1 } & \text { Downstream boundary of segment i } \\ \text { in } & \text { Inlet } \\ \text { out } & \text { Outlet } \\ \text { pred } & \text { Predicted } \\ \text { tp } & \text { Two-phase } \\ \text { ts } & \text { Test section } \\ \text { wall } & \text { Side wall }\end{array}$




\section{Introduction}

Liquid-cooled micro-pin-fin heat sinks utilize micro-size pin-fin arrays as internal heat transfer enhancement structures [1]. Depending on whether boiling of working liquid occurs in the micro-pin-fin arrays, the heat sinks can be classified as single-phase or two-phase (boiling). Effective design and performance assessment of this type of heat sink requires a fundamental knowledge of virtually all aspects of fluid flow and heat transfer in micro-pin-fin arrays. Among others, accurate prediction of pressure drop is of special importance. Due to small flow passages in the micro-scale structures, excessive pressure loss is always a concern. The present study focuses on water pressure drop across a staggered circular micro-pin-fin array. Part 1 of the study, documented in the companion paper [2], reports isothermal liquid single-phase flow results. Part 2, this paper, presents results of adiabatic liquid-vapor two-phase flow.

As the interest in two-phase micro-pin-fin heat sinks is fairly recent, our knowledge on two-phase pressure drop across staggered micro-pin-fin arrays is rather limited [3,4]. Only two studies were found in the literature on pressure drop of adiabatic liquid-gas (vapor) two-phase flow across micro-pin-fin arrays. Krishnamurthy and Peles [3] experimentally studied frictional pressure drop of nitrogen-water two-phase flow across a staggered circular micro-pin-fin array with diameter $D$ of $100 \mu m$, height-to-diameter ratio $H / D$ of 1 , and longitudinal pitch-to-diameter ratio $S_{L} / D$ and transverse pitch-to-diameter ratio $S_{T} / D$ of 1.5 . They found that the existing homogeneous models and Martinelli-Chisholm type correlations were unable to predict the data. Two-phase friction multiplier was found to be a strong function of mass flux. A new MartinelliChisholm type correlation was proposed, where the $C$ factor was linearly proportional to liquid Reynolds number.

Konishi et al. [4] investigated frictional pressure drop of water liquid-vapor two-phase flow across a staggered square micro-pin-fin array with side length $S$ of $200 \mu m, H / S$ of 3.35, and $S_{L} / S$ and $S_{T} / S$ of 2. The existing homogeneous models and Martinelli-Chisholm type correlations were assessed by comparing their predictions with the data. They found that the MartinelliChisholm type correlation with a $C$ factor of 5 provided the best agreement.

There are also a few studies on pressure drop of liquid flow boiling in micro-pin-fin arrays, where vapor qualities increased in the stream-wise direction as a result of heat input. Koşar [5] studied pressure drop of refrigerant R-123 flow boiling in a staggered hydrofoil micropin-fin array with chord thickness $D$ of $100 \mu m$, fin length of $500 \mu m$, and height $H$ of $243 \mu m$. 
$S_{L} / D$ and $S_{T} / D$ were 5 and 1.5 , respectively. They found that the existing homogeneous models and Martinelli-Chisholm type correlations were unable to predict the data. Two-phase friction multiplier was found to be strongly influenced by two-phase flow patterns. Three distinct Martinelli-Chisholm type correlations were proposed for the flow patterns of bubbly, wavyintermittent, and spray-annular.

Qu and Siu-Ho [6] studied pressure drop of water flow boiling in a staggered square micro-pin-fin array with side length $S$ of $200 \mu m, H / S$ of 3.35, and $S_{L} / S$ and $S_{T} / S$ of 2 . They found that the frictional pressure drop in the boiling region was the dominant component. Among the existing models and correlations, the Martinelli-Chisholm type correlation with a $C$ factor of 5 yielded the best agreement with the data.

Reeser et al. [7] investigated pressure drop of water and HFE-7200 flow boiling in two micro-pin-fin arrays: an aligned square and a staggered diamond. Both arrays had pin-fin side length $S$ of $153 \mu \mathrm{m}$ and $H / S$ of $2 . S_{L} / S$ and $S_{T} / S$ were 2 for the aligned array, and 2.8 for the staggered one. They found that the existing Martinelli-Chisholm type correlations were unable to predict the data. Separate Martinelli-Chisholm type correlations were proposed for different combinations of working fluid and pin-fin configuration.

Other relevant studies include those on two-phase frictional pressure drop in conventional size tube banks [8-12]. Most of the studies investigated the aligned tube arrangement except the work by Dowlati et al. [10], in which frictional pressure drop of adiabatic air-water two-phase flow across two staggered tube banks was studied. The tube banks had $D$ of $19.05 \mathrm{~mm}$ and 12.7 $\mathrm{mm}, S_{\mathrm{L}} / \mathrm{D}$ of 1.3 and 1.75 , and $S_{T} / D$ of 1.3 and 1.75 , respectively [10]. They found that the Martinelli-Chisholm type correlation with a $C$ factor of 20 could adequately predict the data for mass flux $G_{\max }>200 \mathrm{~kg} / \mathrm{m}^{2} \mathrm{~s}$. For mass flux $G_{\max }<200 \mathrm{~kg} / \mathrm{m}^{2} \mathrm{~s}$, a strong mass flux effect was observed.

The literature review revealed that the fundamental knowledge on liquid-vapor two-phase pressure drop across micro-pin-fin arrays is rather lacking. The objectives of this part 2 of the study thus are: (1) to provide new data for pressure drop of liquid-vapor two-phase flow across micro-pin-fin arrays, (2) to examine the relationship between two-phase friction multiplier and Martinelli parameter, and assess the feasibility of using Lockhart and Martinelli's generalized procedure [13] to predict two-phase flow pressure drop across the micro-pin-fin array, (3) to 
assess the accuracy of the existing correlations at predicting the present data, and (4) to develop a new predictive tool.

\section{Experimental Apparatus and Procedure}

The same micro-pin-fin test module used in part 1 [2] for the experimental study of single-phase pressure drop was employed here to investigate two-phase pressure drop. Figure 1 shows a schematic of the test module, which is composed of a test section, a housing, and a transparent cover plate. The test section had a top platform area of $1 \mathrm{~cm}$ (width) by $3.38 \mathrm{~cm}$ (length). An array of 1845 staggered circular micro-pin-fins was milled out of the platform surface. There were 82 rows in the longitudinal (stream-wise) direction, 23 pin-fins in every odd row, and 22 pin-fins in every even row. The micro-pin-fins were $180 \mu \mathrm{m}$ in diameter $D, 683 \mu \mathrm{m}$ in height $H$, and $399 \mu \mathrm{m}$ in both longitudinal pitch $S_{L}$ and transverse pitch $S_{T}$. The resulting $H / D$ ratio was 3.8, and $S_{L} / D$ and $S_{T} / D$ ratios 2.2 .

The housing contained inlet and outlet plenums, each consisting of a shallow and a deep section. The inlet and outlet deep plenums had a width of $19 \mathrm{~mm}$ and a height of $15.9 \mathrm{~mm}$ while the shallow plenums a width of $19 \mathrm{~mm}$ and a height of $670 \mu \mathrm{m}$. Two type-K thermocouples were installed in the deep plenums to measure the inlet and outlet temperatures $T_{\text {in }}$ and $T_{\text {out, }}$ respectively. An absolute pressure transducer was connected to the inlet deep plenum to measure the test section inlet pressure $P_{i n}$. A differential pressure transducer was connected to the inlet and outlet deep plenums to measure the pressure drop across the test section $\Delta P_{t p}$. The assembled test module was wrapped with multiple layers of fiberglass insulation material to minimize heat loss to the surroundings so as to maintain an adiabatic condition in the micro-pinfin array. Further details of the micro-pin-fin array, test module, and instrumentations can be found in part 1 [2], and are omitted in this paper for brevity.

The flow loop described in part 1 [2] was modified to accommodate the two-phase testing. As shown in Fig. 2(a), an inline vapor generator was installed just upstream of the test module. The vapor generator consisted of a cylindrical immersion heater installed concentrically inside an outer pipe of larger diameter. The working fluid flowed through the gap between the immersion heater and outer pipe. Figure 2(b) shows a schematic of the vapor generator. The immersion heater was powered by a 0-110 VAC transformer to vary the input heating power to desired levels. A compact heat exchanger (Heat Exchanger 2) that was connected to a constant 
temperature bath was employed to increase the temperature of the testing water to about $90{ }^{\circ} \mathrm{C}$ before the water entered the vapor generator. The temperature of the water stream prior to entering the vapor generator $T_{v g \text {,in }}$ was measured by a $K$-type thermocouple. The liquid water was vaporized into a saturated liquid-vapor two-phase mixture in the vapor generator by supplying heating power $P_{W, v g}$ to the immersion heater. $P_{W, v g}$ was measured with a precision wattmeter whose accuracy is $0.5 \%$ of the readings. The vapor generator was also well wrapped with fiberglass material to minimize heat loss. The two-phase mixture leaving the vapor generator entered the test module for testing. After the test module, the mixture passed through another heat exchanger (Heat Exchanger 3) to condense any vapor back to liquid before it returned to the reservoir.

The water in the reservoir was deaerated for one hour prior to a testing run through vigorous boiling to force any dissolved gases to escape to the ambient. The reservoir was maintained at the boiling condition throughout all testing runs. Seven maximum mass velocities $G_{\max }$ were tested, ranging from 171 to $491 \mathrm{~kg} / \mathrm{m}^{2} \mathrm{~s}$. $G_{\max }$ was calculated based on the minimum transverse flow area $A_{\min }$ in the micro-pin-fin array,

$$
G_{\max }=\frac{\dot{m}}{A_{\min }} .
$$

Calculation of $A_{\min }$ for the present micro-pin-fin array can be found in part 1 [2]. At each $G_{\max }$, $P_{W, v g}$ was progressively increased from low to high levels by adjusting the transformer to yield a range of vapor qualities in the two-phase mixtures. The following equation is used to determine thermodynamic equilibrium quality of the two-phase mixture at the test section inlet $x_{e, i n}$ :

$$
x_{e, i n}=\frac{\dot{m} h_{v g, i n}+P_{W, v g}-Q_{l o s s, v g}}{\dot{m} h_{f g, i n}},
$$

where $h_{v g, \text { in }}$ is the enthalpy of the liquid water upstream of the vapor generator based on $T_{v g \text {,in }}$,

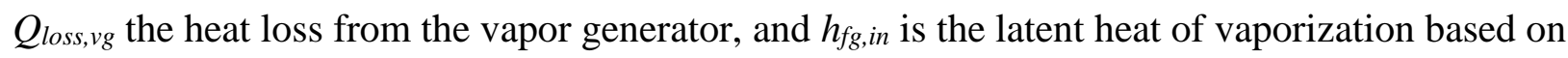
the measured test section inlet pressure $P_{i n}$. Heat losses from the vapor generator and test module, $Q_{\text {loss,vg }}$ and $Q_{\text {loss,ts, }}$ respectively, were characterized from a series of single-phase tests running $90^{\circ} \mathrm{C}$ liquid water through the two loop components. Qloss,vg ranged from 9.2 to $11.4 \mathrm{~W}$, and $Q_{\text {loss,ts }}$ from 6.7 to $9.4 \mathrm{~W}$. The heat losses were minuscule as compared to $P_{W, v g}$ for most of the testing runs, i.e., $Q_{\text {loss,vg }}$ was $1.3 \%-16.2 \%$ of $P_{W, v g}$ with an average of $2.9 \%$ while $Q_{\text {loss,ts }} 0.9 \%$ $9.5 \%$ of $P_{W, v g}$ with an average of $2.4 \%$. For the present study, $x_{e, \text { in }}$ had a maximum value of 0.46 for the lowest $G_{\max }$ of $171 \mathrm{~kg} / \mathrm{m}^{2} \mathrm{~s}$, and 0.11 for the highest $G_{\max }$ of $491 \mathrm{~kg} / \mathrm{m}^{2} \mathrm{~s}$. 
The flow was allowed to reach steady state at each $G_{\max }$ and $P_{W, v g}$. Once at steady state, readings from flow meters, thermocouples, and pressure transducers were recorded at 0.5-second intervals for 3 minutes using a data acquisition system. A LABVIEW program was then used to output the data into a spreadsheet format. Readings from the wattmeter and rotameters were recorded manually.

\section{Results and Discussion}

\subsection{Pressure drop}

The measured two-phase pressure drop $\Delta P_{t p}$ versus $x_{e, \text { in }}$ for the seven tested $G_{\text {max }}$ is presented in Fig. 3. For a fixed $G_{\max }, \Delta P_{t p}$ increases substantially with increasing $\chi_{e, i n}$, indicative of a strong impact of presence of the vapor phase on pressure drop. For a given $x_{e, i n}, \Delta P_{t p}$ increases appreciably as $G_{\max }$ increases.

As discussed in part 1 [2], $\Delta P_{t p}$, being the pressure drop across the test section, is composed of five components: an inlet contraction loss from the deep plenum to the shallow plenum $\Delta P_{c 1}$, an inlet contraction loss from the shallow plenum to the test section inlet $\Delta P_{c 2}$, two-phase pressure drop across the micro-pin-fin array $\Delta P_{t p, f i n}$, an outlet expansion recovery from the test section outlet to the shallow plenum $\Delta P_{e 2}$, and an outlet expansion recovery from the shallow plenum to the deep plenum $\Delta P_{e 1}$.

$$
\Delta P_{t p}=\Delta P_{c 1}+\Delta P_{c 2}+\Delta P_{t p, f i n}+\Delta P_{e 2}+\Delta P_{e 1} .
$$

The inlet losses and outlet recoveries are calculated from the following equations [2,14,15],

$$
\begin{gathered}
\Delta P_{c 1}=\frac{v_{f, \text { in }}+x_{e, \text { in }} v_{f g, \text { in }}}{2}\left(G_{p 2}^{2}-G_{p 1}^{2}\right)+\frac{K_{c 1}\left(v_{f, \text { in }}+x_{e, \text { in }} v_{f, \text { in }}\right)}{2} G_{p 2}^{2}, \\
\Delta P_{c 2}=\frac{v_{f, \text { in }}+x_{e, \text { in }} v_{f g, \text { in }}}{2}\left(G_{t s}^{2}-G_{p 2}^{2}\right)+\frac{K_{c 2}\left(v_{f, \text { in }}+x_{e, \text { in }} v_{f g, \text { in }}\right)}{2} G_{t s}^{2}, \\
\Delta P_{e 2}=\frac{v_{f, \text { out }}+x_{e, \text { out }} v_{f g, \text { out }}}{2}\left(G_{p 2}^{2}-G_{t s}^{2}\right)+\frac{K_{e 2}\left(v_{f, \text { out }}+x_{e, \text { out }} v_{f g, \text { out }}\right)}{2} G_{t s}^{2},
\end{gathered}
$$

and

$$
\Delta P_{e 1}=\frac{v_{f, \text { out }}+x_{e, \text { out }} v_{f g, \text { out }}}{2}\left(G_{p 1}^{2}-G_{p 2}^{2}\right)+\frac{K_{e 1}\left(v_{f, \text { out }}+x_{e, \text { out }} v_{f g, \text { out }}\right)}{2} G_{p 2}^{2} .
$$

All material properties at the inlet were evaluated based on the measured $P_{i n}$, while properties at the outlet based on $P_{\text {out }}$.

$$
P_{\text {out }}=P_{\text {in }}-\Delta P_{t p}
$$


Calculations of all the mass velocities $G_{p 1}, G_{p 2}, G_{t s}$ and coefficients $K_{c 1}, K_{c 2}, K_{e 2}, K_{e 1}$ can be found in part 1 [2]. $x_{e, \text { out }}$ in Eqs. (6) and (7) represents the mixture thermodynamic equilibrium quality at the test section outlet,

$$
x_{e, \text { out }}=\frac{\dot{m} h_{v g, \text { in }}+P_{W, v g}-\left(Q_{\text {loss }, v g}+Q_{\text {loss }, t s}\right)}{\dot{m} h_{f g, o u t}},
$$

The total contraction loss $\Delta P_{c 1}+\Delta P_{c 2}$ accounts for $2.4 \%-9.9 \%$ of $\Delta P_{t p}$, while the overall expansion recovery $\left|\Delta P_{e 2}+\Delta P_{e 1}\right|$ accounts for $1.4 \%-4.4 \%$ of $\Delta P_{t p}$.

Once all the loss and recovery components are calculated from Eqs. (4)-(7), $\Delta P_{t p, f i n}$ can be determined from

$$
\Delta P_{t p, f i n}=\Delta P_{t p}-\left(\Delta P_{c 1}+\Delta P_{c 2}+\Delta P_{e 2}+\Delta P_{e 1}\right) .
$$

The pressures at the inlet and outlet of the micro-pin-fin array $P_{\text {fin,in }}$ and $P_{\text {fin,out }}$ are calculated from

$$
P_{f i n, i n}=P_{i n}-\left(\Delta P_{c 1}+\Delta P_{c 2}\right),
$$

and

$$
P_{\text {fin, out }}=P_{\text {out }}+\left(\Delta P_{e 2}+\Delta P_{e 1}\right) .
$$

\subsection{Two-phase friction multiplier and Martinelli parameter}

Lockhart and Martinelli proposed in their classic paper [13] a generalized procedure for calculating frictional pressure gradient of adiabatic liquid-gas two-phase flow in pipes. In the treatment, the two-phase frictional pressure gradient was calculated from

$$
-\left(\frac{d P}{d z}\right)_{F, t p}=-\left(\frac{d P}{d z}\right)_{F, f} \phi_{f, p i p e}^{2}
$$

where - $(d P / d z)_{F, f}$ is the frictional pressure gradient of single-phase liquid flow in the pipe based on the actual liquid flow rate through the whole pipe cross-sectional area, and $\phi_{f, p i p e}$ two-phase friction multiplier. Lockhart and Martinelli found that $\phi_{f, p i p e}$ could be correlated uniquely as a function of a Martinelli parameter $X_{\text {pipe }}$, which was defined as

$$
X_{\text {pipe }}=\sqrt{\frac{-(d P / d z)_{F, f}}{-(d P / d z)_{F, g}}}
$$

where - $(d P / d z)_{F, g}$, similar to $-(d P / d z)_{F, f}$, represents the frictional pressure gradient of single-phase gas flow based on the actual gas flow rate through the whole area. $X_{\text {pipe }}$ could be predetermined once the flow condition was known. The correlation was presented in a graphical format where $\phi_{f, \text { pipe }}$ was plotted versus $X_{\text {pipe }}$ on a log-log scale [13]. An important feature of the Lockhart and 
Martinelli correlation is that it was not tied to any specific two-phase flow patterns, and depended only upon flow regimes, i.e., viscous (laminar) or turbulent, of the two phases.

Chisholm and Laird later proposed a simple formula to represent Lockhart and Martinelli's graphical correlation [16]. The Martinelli-Chisholm correlation took the form

$$
\phi_{f, p i p e}^{2}=1+\frac{C}{X_{\text {pipe }}}+\frac{1}{X_{\text {pipe }}^{2}},
$$

where $C$ is called $C$ factor, and is an empirical constant whose value depends on flow regimes of the two respective phases: $C=5$ for laminar liquid and laminar gas, 12 for laminar liquid and turbulent gas, 10 for turbulent liquid and laminar gas, and 20 for turbulent liquid and turbulent gas. The correlation displays the following asymptotic behavior as required by the definition of $\phi_{\text {fpipe }}$ and $X_{\text {pipe }}$ [17]: as $x \rightarrow 0\left(X_{\text {pipe }} \rightarrow \infty\right), \phi_{f, p i p e} \rightarrow 1$, thus $-(d P / d z)_{F, t p} \rightarrow-(d P / d z)_{F, f}$; as $x \rightarrow 1\left(X_{\text {pipe }} \rightarrow 0\right)$, $\phi_{f, p i p e} \rightarrow \frac{1}{X_{\text {pipe }}}$, thus $-(d P / d z)_{F, t p} \rightarrow-(d P / d z)_{F, g}$.

The Martinelli-Chisholm type correlation, despite being originally developed for pipe flow, has been applied in a number of studies to describe pressure drop of liquid-vapor twophase flow across staggered micro-pin-fin arrays and tube banks as summarized in the introduction section. The $C$ factor was often modified from its original values for pipe flow to accommodate specific geometrical configurations and flow conditions.

In this study, two-phase friction multiplier $\phi_{\uparrow}$ and Martinelli parameter $X$ were determined for the present micro-pin-fin array, and their relationship discussed. A number of simplifying approximations were introduced to facilitate the calculation of the two parameters. The twophase flow across the micro-pin-fin array was adiabatic in the present study. With the absence of heat input, one would expect the variation of flow quality in the longitudinal (stream-wise) direction to be small. It was therefore assumed that the two-phase pressure drop was caused solely by frictional effects as a result of wall friction and drag force exerted on the flow by the micro-pin-fins, and contribution from flow acceleration due to flow quality variation was negligible. In addition, single averaged values were employed to represent the material properties as well as vapor quality. Effects of flow acceleration and property variations as a result of the change in local fluid pressure along the longitudinal direction are accounted for later in the paper.

The following equations are employed to calculate $\phi_{f}$ and $X$ : 


$$
\phi_{f}=\sqrt{\frac{\Delta P_{t p, f i n}}{\Delta P_{f, f i n}}}
$$

and

$$
X=\sqrt{\frac{\Delta P_{f, \text { fin }}}{\Delta P_{g, f \text { in }}}}
$$

Two-phase pressure drop across the micro-pin-fin array $\Delta P_{t p, f i n}$ in Eq. (16) is from Eq. (10). $\Delta P_{f, f i n}$ and $\Delta P_{g, f i n}$ in the two equations represent liquid and vapor single-phase pressure drop across the micro-pin-fin array, respectively, based on the actual flow rate of each phase, and are evaluated from

$$
\Delta P_{f, f i n}=f_{f, f i n} N_{L}\left[\frac{v_{f} G_{\max }^{2}\left(1-x_{e, a v e}^{2}\right)}{2}\right]
$$

and

$$
\Delta P_{g, f i n}=f_{g, f i n} N_{L}\left[\frac{v_{g} G_{m a x}^{2} x_{e, a v e}^{2}}{2}\right],
$$

where $N_{L}$ is the total number of pin-fin rows in the longitudinal direction $\left(N_{L}=82\right)$, and $f_{f, f i n}$ and $f_{g, f i n}$ liquid and vapor single-phase friction factor, respectively, based on the actual flow rates. $f_{f, f i n}$ and $f_{g, f i n}$ are calculated using the single-phase friction factor correlation developed in part 1 for the present micro-pin-fin array [2]:

$$
f_{f, \text { fin }}=4.0947 \times 10^{-1}+\frac{3.9808 \times 10^{1}}{R e_{f}}+\frac{7.2713 \times 10^{2}}{R e_{f}^{2}}-\frac{2.5465 \times 10^{4}}{R e_{f}^{3}}+\frac{1.2565 \times 10^{5}}{R e_{f}^{4}},
$$

and

$$
f_{g, f \text { in }}=4.0947 \times 10^{-1}+\frac{3.9808 \times 10^{1}}{R e_{g}}+\frac{7.2713 \times 10^{2}}{R e_{g}^{2}}-\frac{2.5465 \times 10^{4}}{R e_{g}^{3}}+\frac{1.2565 \times 10^{5}}{R e_{g}^{4}} .
$$

In Eqs. (20) and (21), $R e_{f}$ and $R e_{g}$ denote liquid and vapor Reynolds number, respectively, based on actual flow rates,

$$
R e_{f}=\frac{G_{\max }\left(1-x_{e, a v e}\right) D}{\mu_{f}}
$$

and

$$
R e_{g}=\frac{G_{\max } x_{e, a v e} D}{\mu_{g}} .
$$

$R e_{f}$ ranged from 66 to 321, and $R e_{g}$ from 45 to 1,132 in the present study.

All properties in Eqs. (16)-(23) are evaluated based on the average of $P_{\text {fin,in }}$ and $P_{\text {fin,out }}$.

$$
P_{\text {ave }}=\frac{P_{\text {fin }, \text { in }}+P_{\text {fin }, \text { out }}}{2} \text {. }
$$




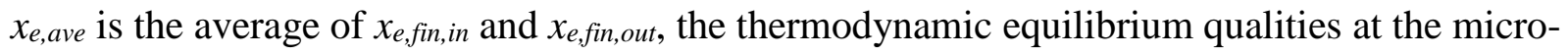
pin-fin array inlet and outlet, respectively,

$$
x_{e, \text { ave }}=\frac{x_{e, \text { fin }, \text { in }}+x_{e, \text { fin }, \text { out }}}{2},
$$

where $x_{e, \text { fin,in }}$ and $x_{e, \text { fin,out }}$ are determined from

$$
x_{e, f i n, i n}=\frac{\dot{m} h_{v g, i n}+P_{W, v g}-Q_{l o s s, v g}}{\dot{m} h_{f g, f i n, i n}},
$$

and

$$
x_{e, f i n, o u t}=\frac{\dot{m} h_{v g, i n}+P_{W, v g}-\left(Q_{l o s s, v g}+Q_{l o s s, t s}\right)}{\dot{m} h_{f g, f i n, o u t}} .
$$

$\phi_{f}$ is plotted against $X$ on a log-log scale in Fig. 4 for all the conditions tested in this

study. It is seen that $\phi_{f}$ can be correlated very well by $X$ with little scatter in the data, revealing a unique functional relationship between the two parameters. The result demonstrates that the generalized procedure proposed by Lockhart and Martinelli [13] could be applied to describe water liquid-vapor two-phase pressure drop across the present micro-pin-fin array.

\subsection{Correlation method}

Konishi et al. [4] applied the Martinelli-Chisholm type correlation with a $C$ factor of 5 to predict water liquid-vapor two-phase pressure drop across a staggered square micro-pin-fin array, and found the predictions agreed fairly well with the data. Dowlati et al. [11] found the Martinelli-Chisholm type correlation with a $C$ factor of 20 could adequately predict their pressure drop data of adiabatic air-water two-phase flow across staggered tube banks for $G_{\max }>$ $200 \mathrm{~kg} / \mathrm{m}^{2} \mathrm{~s}$. Figure 5 presents the experimental $\phi_{f}$ versus $X$ along with the predictions from the Martinelli-Chisholm type correlations with $C$ factor of 5 and 20, respectively. It can be seen that while both correlations overpredict the present data, predictions from the one with $C=5$ are much closer to the experimental results.

A Martinelli-Chisholm type correlation was developed by Krishnamurthy and Peles [3] based on their pressure drop data of adiabatic nitrogen-water two-phase flow across a staggered circular micro-pin-fin array. In the correlation, the $C$ factor was set to be linearly proportional to liquid Reynolds number. Figure 6 compares the correlation predictions with the experimental data. The result indicates significant discrepancies between the correlation predictions and data except in the low $X$ region, which corresponds to the testing conditions of low $G_{\max }$ and high $x_{e, \text { in }}$. 
The discrepancies may be attributed to the fact that the Krishnamurthy and Peles correlation was developed for low liquid Reynolds number flow, i.e., $R e_{f}$ ranged from 5 to 50.

The poor agreement between the existing correlation predictions and the present data promote the development of a new correlation that describes the functional relationship between $\phi_{f}$ and $X$ for the present micro-pin-fin array. An attempt was first made to use the format of the Martinelli-Chisholm type correlation, Eq. (15), and seek a well-suited constant value for the $C$ factor. The following equation is used to calculate values of $C$ from the $\phi_{f}$ and $X$ data:

$$
C=\left(\phi_{f}^{2}-1-\frac{1}{X^{2}}\right) X .
$$

Figure 7 shows the variation of the calculated $C$ factor with $X$. The large scatter in the data led to the conclusion that no singular constant value of $C$ for the Martinelli-Chisholm type correlation could be identified that was suitable for the entire parametric range of present data. Alternative formats were explored, which ultimately yielded the following equation:

$$
\phi_{f}^{2}=1+\frac{2.1675}{X^{0.76}}+\frac{1}{X^{2}} .
$$

The constants 2.1675 and 0.76 in the new correlation were obtained from non-linear least squares regression. Figure 8 shows Eq. (29) plotted with the $\phi_{f}$ versus $X$ data. It should be noted that the new correlation exhibits the same asymptotic behavior as the original Martinelli-Chisholm correlation, Eq. (15).

\subsection{Assessment of the new correlation}

The new correlation was applied to calculate two-phase pressure drop across the micropin-fin array $\Delta P_{t p, f i n}$. Effects of property variations and flow acceleration, induced by substantial pressure decreases in the longitudinal direction, were accounted for in the calculations using a segment-based technique $[4,6]$.

$\Delta P_{t p, f i n}$ thus consists of a frictional component $\Delta P_{F, f i n}$ and an accelerational component $\Delta P_{A, f i n}$.

$$
\Delta P_{t p, f i n}=\Delta P_{F, \text { fin }}+\Delta P_{A, f i n} .
$$

The two components are calculated from

$$
\Delta P_{F, f i n}=\sum_{i=1}^{N_{L}} \Delta P_{F, i}=\sum_{i=1}^{N_{L}}\left[f_{f, i} \frac{v_{f, i} G_{\max }^{2}\left(1-x_{e, i}\right)^{2}}{2} \phi_{f, i}\right],
$$

and 


$$
\Delta P_{A, f i n}=\sum_{i=1}^{N_{L}} \Delta P_{A, i}=\sum_{i=1}^{N_{L}} G_{\min }^{2}\left\{\begin{array}{l}
{\left[\frac{x_{e, i b d 1}^{2} v_{g, i b d 1}}{\alpha_{i b d 1}}-\frac{\left(1-x_{e, i b d 1}\right)^{2} v_{f, i b d 1}}{1-\alpha_{i b d 1}}\right]} \\
-\left[\frac{x_{e, i b d 0}^{2} v_{g, i b d 0}}{\alpha_{i b d 0}}-\frac{\left(1-x_{e, i b d 0}\right)^{2} v_{f, i b d 0}}{1-\alpha_{i b d 0}}\right]
\end{array}\right\},
$$

where subscript $i$ denotes a segment in the stream-wise direction that contains a row of micropin-fins together with the surrounding portion of the top and bottom end walls as shown in Fig. 9, and subscripts $i b d 0$ and $i b d 1$ the upstream and downstream boundary of the segment $i$, respectively. Liquid single-phase friction factor based on the actual flow rate $f_{f}$, two-phase friction multiplier $\phi_{f}$, and thermodynamic equilibrium qualities $x_{e}$ in the segment $i$ are determined following Eqs. (20), (29), (25)-(27), respectively. $G_{\min }$ in Eq. (32) denotes the water mass velocity at the boundaries of the segment $i$, and is evaluated from

$$
G_{\text {min }}=\frac{\dot{m}}{A_{\max }}=\frac{\dot{m}}{H\left(W-2 W_{\text {wall }}\right)} \text {. }
$$

$\alpha$ in Eq. (32) represents void fraction, and is related to $x_{e}$ using Zivi’s correlation [18].

$$
\alpha=\frac{1}{1+\left(\frac{1-x_{e}}{x_{e}}\right)\left(\frac{v_{f}}{v_{g}}\right)^{2 / 3}} .
$$

Calculations of $\Delta P_{F, \text { fin }}$ and $\Delta P_{A, \text { fin }}$ using Eq. (31) and (32), respectively, commences at the micro-pin-fin array inlet with local pressure $P_{\text {fin,in }}$, and proceeds progressively downstream. All material properties in the segment $i$ are determined based on the local pressure $P_{i}$ that is evaluated from

$$
P_{i}=\frac{P_{i b d 0}+P_{i b d 1}}{2}
$$

where

$$
P_{i b d 1}=P_{i b d 0}-\left(\Delta P_{F, i}+\Delta P_{A, i}\right)
$$

An iterative technique was applied to determine pressures and material properties in each segment $i$.

Once $\Delta P_{t p, \text { fin }}$ is calculated from Eq. (30), it is substituted into Eq. (3) to evaluate the overall pressure drop across the test section $\Delta P_{t p}$. Figure 10 compares the $\Delta P_{t p}$ data with the predicted values, and shows a good agreement with a mean absolute error (MAE) of 7.98\%. Definition of $M A E$ can be found in part 1 [2].

To reveal the contribution of each pressure drop component to $\Delta P_{t p}$, the predicted $\Delta P_{F, f i n}$, $\Delta P_{A, f i n}, \Delta P_{c}\left(=\Delta P_{c 1}+\Delta P_{c 2}\right)$, and $\Delta P_{e}\left(=\Delta P_{e 2}+\Delta P_{e 1}\right)$ are plotted versus $x_{e, \text { in }}$ in Fig. 11 for $G_{\max }=171$ $\mathrm{kg} / \mathrm{m}^{2} \mathrm{~s}$. Also presented in Fig. 11 are the measured and predicted $\Delta P_{t p}$, which show a fairly good 
agreement. The result confirms that $\Delta P_{F, f i n}$ is the dominant component and all other components are minuscule. This validates the prior assumption of negligible $\Delta P_{A, f i n}$ when $\phi_{f}$ and $X$ were calculated from the data.

\section{Conclusions}

Pressure drop characteristics of water adiabatic liquid-vapor two-phase flow across a staggered circular micro-pin-fin array were investigated experimentally. The applicability of the generalized procedure developed by Lockhart and Martinelli [13] at describing two-phase

pressure drop across the micro-pin-fin array was assessed. Also presented was an assessment of existing correlations at predicting the data. Key finding from the study are as follows:

1. Two-phase pressure drop increased drastically with increasing vapor quality, demonstrating a strong impact of vapor content.

2. A unique functional relationship was identified between two-phase friction multiplier and Martinelli parameter. This indicates that the generalized procedure developed by Lockhart and Martinelli [13] can be applied to predict liquid-vapor two-phase pressure drop across the present micro-pin-fin array.

3. The existing Martinelli-Chisholm type correlations for staggered micro-pin-fin arrays and tube banks were unable to accurately predict the experimental data, and a new correlation was developed. The new correlation shared the same asymptotic behavior as the original Martinelli-Chisholm correlation [16].

\section{Acknowledgement}

The authors are grateful for the support of the National Science Foundation (NSF) (Award no. CBET10-34242). The micro-pin-fin test section was fabricated at the Laser-Assisted Multi-Scale Manufacturing Laboratory, University of Wisconsin-Madison. Professor Frank Pfefferkorn's assistance in fabricating the test section was greatly appreciated. 


\section{References}

[1] B.A. Jasperson, Y. Jeon, K.T. Turner, F.E. Pfefferkorn, W. Qu, Comparison of micropin-fin and micro-channel heat sinks considering thermal-hydraulic performance and manufacturability, IEEE Transactions on Components and Packaging Technologies 33 (2010) 148-160.

[2] J. Mita, W. Qu, Pressure drop of water flow across a micro-pin-fin array part 1: isothermal liquid single-phase flow, International Journal of Heat and Mass Transfer, in review.

[3] S. Krishnamurthy, Y. Peles, Gas-liquid two-phase flow across a bank of micropillars, Physics of Fluids 19(4) (2007) 043302-1-043302-14.

[4] C.A. Konish, W. Qu, F.E. Pfefferkorn, Experimental study of water liquid-vapor twophase pressure drop across an array of staggered micropin-fins, ASME Journal of Electronic Packaging 131 (2009) 021010-1-021010-8.

[5] A. Koşar, Two-phase pressure drop across a hydrofoil-based micro pin device using R123, Experimental Thermal and Fluid Science 32 (2008) 1213-1221.

[6] W. Qu, A.M. Siu-Ho, Measurement and prediction of pressure drop in a two-phase micro-pin-fin heat sink, International Journal of Heat and Mass Transfer 52 (2009) 51735184.

[7] A. Reeser, A. Bar-Cohen, G. Hetsroni, High quality flow boiling heat transfer and pressure drop in microgap pin fin arrays, International Journal of Heat and Mass Transfer 78 (2014) 974-985.

[8] K. Ishihara, J.W. Palen, J. Taborek, Critical review of correlations for predicting twophase flow pressure drop across tube banks, Heat Transfer Engineering 1(3) (1980) 2332.

[9] D.S. Schrage, J.-T. Hsu, M.K. Jensen, Two-phase pressure drop in vertical crossflow across a horizontal tube bundle, AIChE Journal 34(1) (1988) 107-115.

[10] R. Dowlati, A.M.C. Chan, M. Kawaji, Hydrodynamics of two-phase flow across horizontal in-line and staggered rod bundles, ASME Journal of Fluids Engineering 114 (1992) 450-456.

[11] R. Dowlati, M. Kawaji, A.M.C. Chan, Two-phase crossflow and boiling heat transfer in horizontal tube bundles, ASME Journal of Heat Transfer 118 (1) (1996) 124-131. 
[12] G.P. Xu, K.W. Tou, C.P. Tso, Two-phase void fraction and pressure drop in horizontal crossflow across a tube bundle, ASME Journal of Heat Transfer 120 (1998) 140-145.

[13] R.W. Lockhart, R.C. Martinelli, Proposed correlation of data for isothermal two-phase, two-component flow in pipes, Chemical Engineering Progress 45 (1949) 39-48.

[14] R.D. Blevins, Applied Fluid Dynamics Handbook, Van Nostrand Reinhold Company, New York, 1984.

[15] J.G. Collier, J.R. Thome, Convective Boiling and Condensation, 3rd edition, Oxford University Press, Oxford, 1994.

[16] D. Chisholm, A.D.K. Laird, Two-phase flow in rough tubes, Transactions of the ASME 80 (1958) 276-286.

[17] V.P. Carey, Liquid-Vapor Phase-Change Phenomena, Hemisphere Publishing corporation, Washington DC, 1992.

[18] S.M. Zivi, estimation of steady-state steam void fraction by means of the principle of minimum entropy production, ASME Journal of Heat Transfer 86 (1964) 247-252. 


\section{Figure Captions}

Fig. 1: $\quad$ Test module construction.

Fig. 2: $\quad$ Schematics of (a) flow loop and (b) vapor generator.

Fig. 3: $\quad$ Measured pressure drop versus test section inlet vapor quality.

Fig. 4: $\quad$ Two-phase friction multiplier versus Martinelli parameter.

Fig. 5: Comparison of two-phase friction multiplier data with predictions from the Martinelli-Chisholm type correlation with the $C$ factor of 5 and 20.

Fig. 6: Comparison of two-phase friction multiplier data with predictions from the Krishnamurthy and Peles correlation.

Fig. 7: $\quad$ Variation of the $C$ factor with Martinelli parameter.

Fig. 8: Comparison of two-phase friction multiplier data with predictions from the new correlation.

Fig. 9: $\quad$ Schematic of a segment in micro-pin-fin array.

Fig. 10: Comparison of pressure drop data with correlation predictions.

Fig. 11: Contribution of individual pressure drop component to overall test section pressure drop 

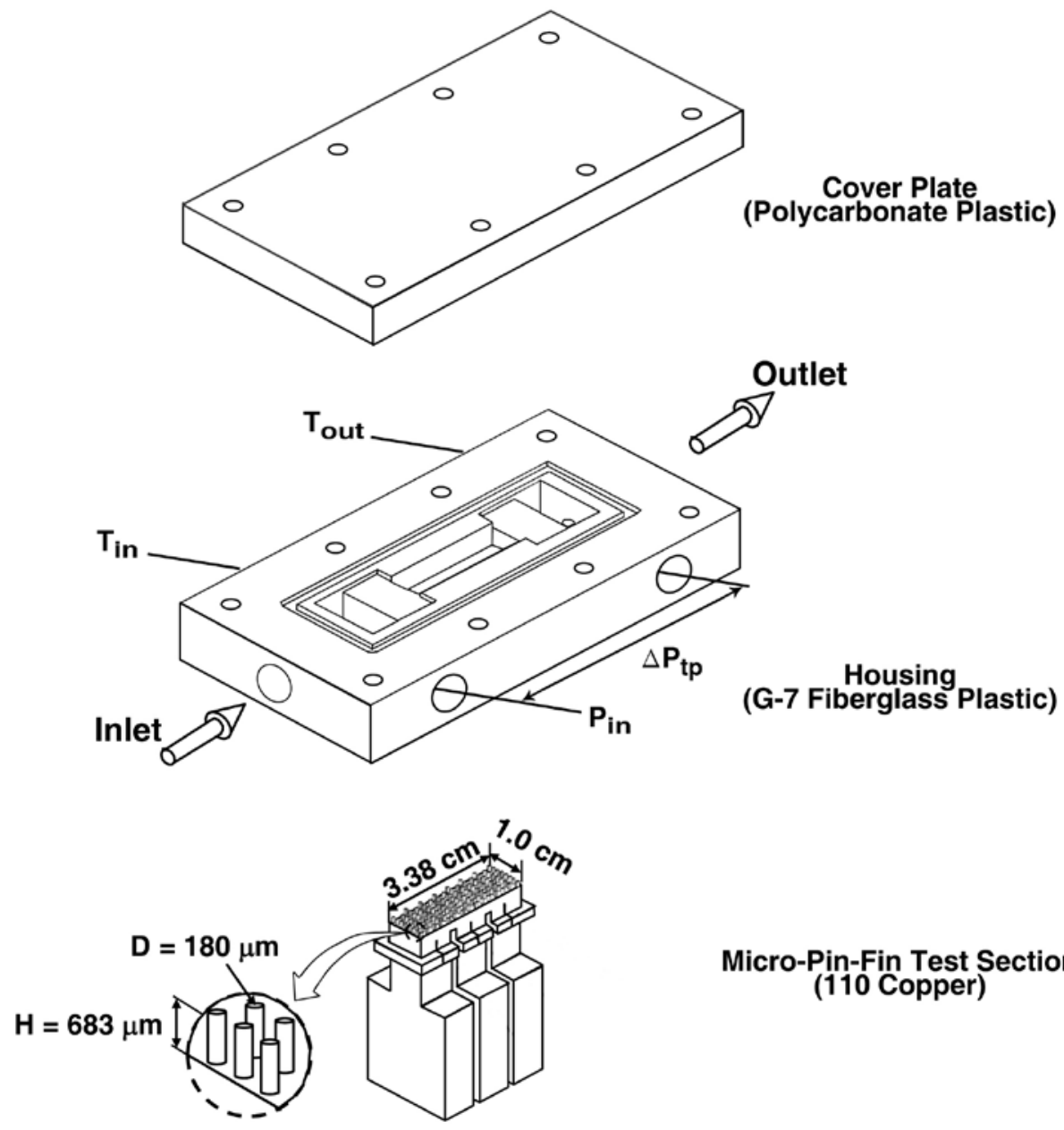

Micro-Pin-Fin Test Section (110 Copper)

Figure 1 


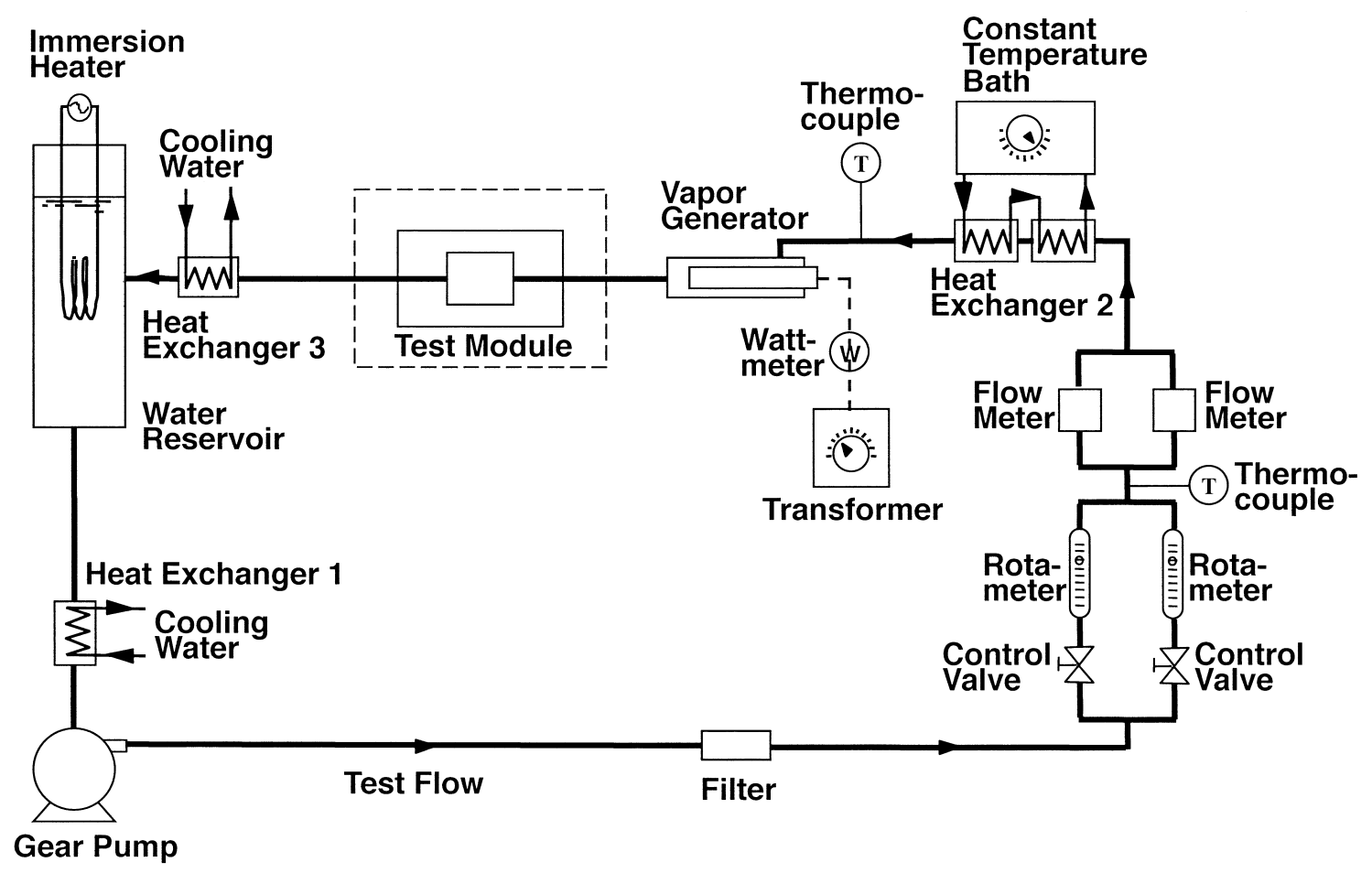

(a)

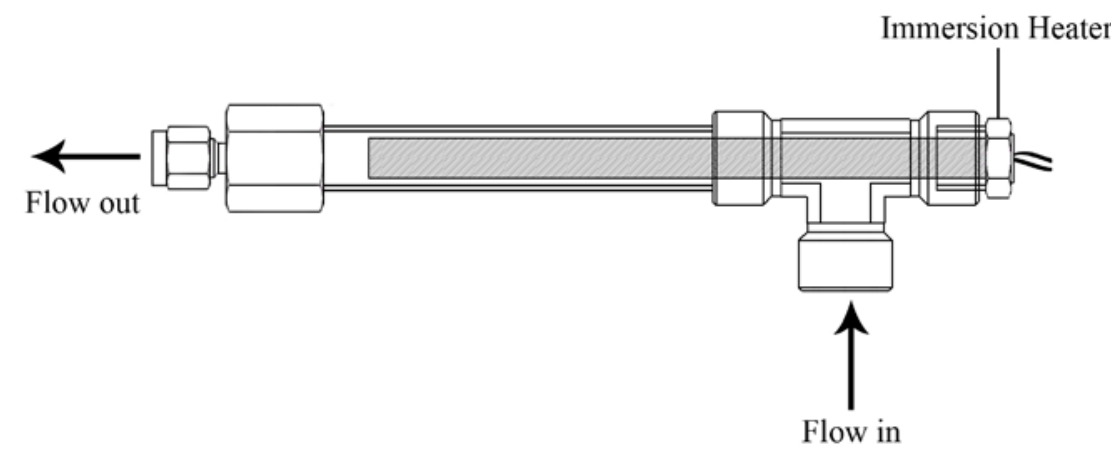

(b)

Figure 2 


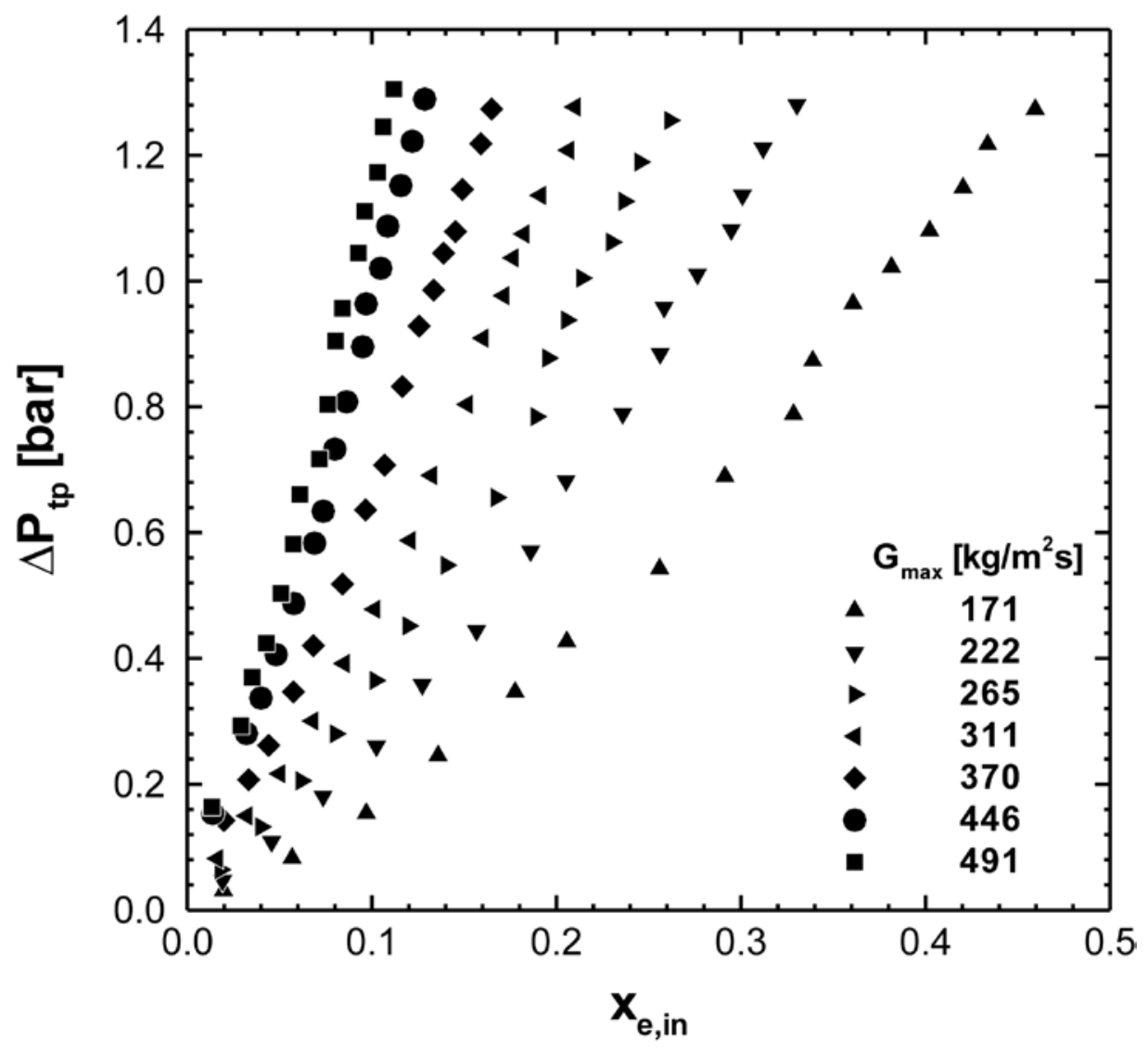

Figure 3 


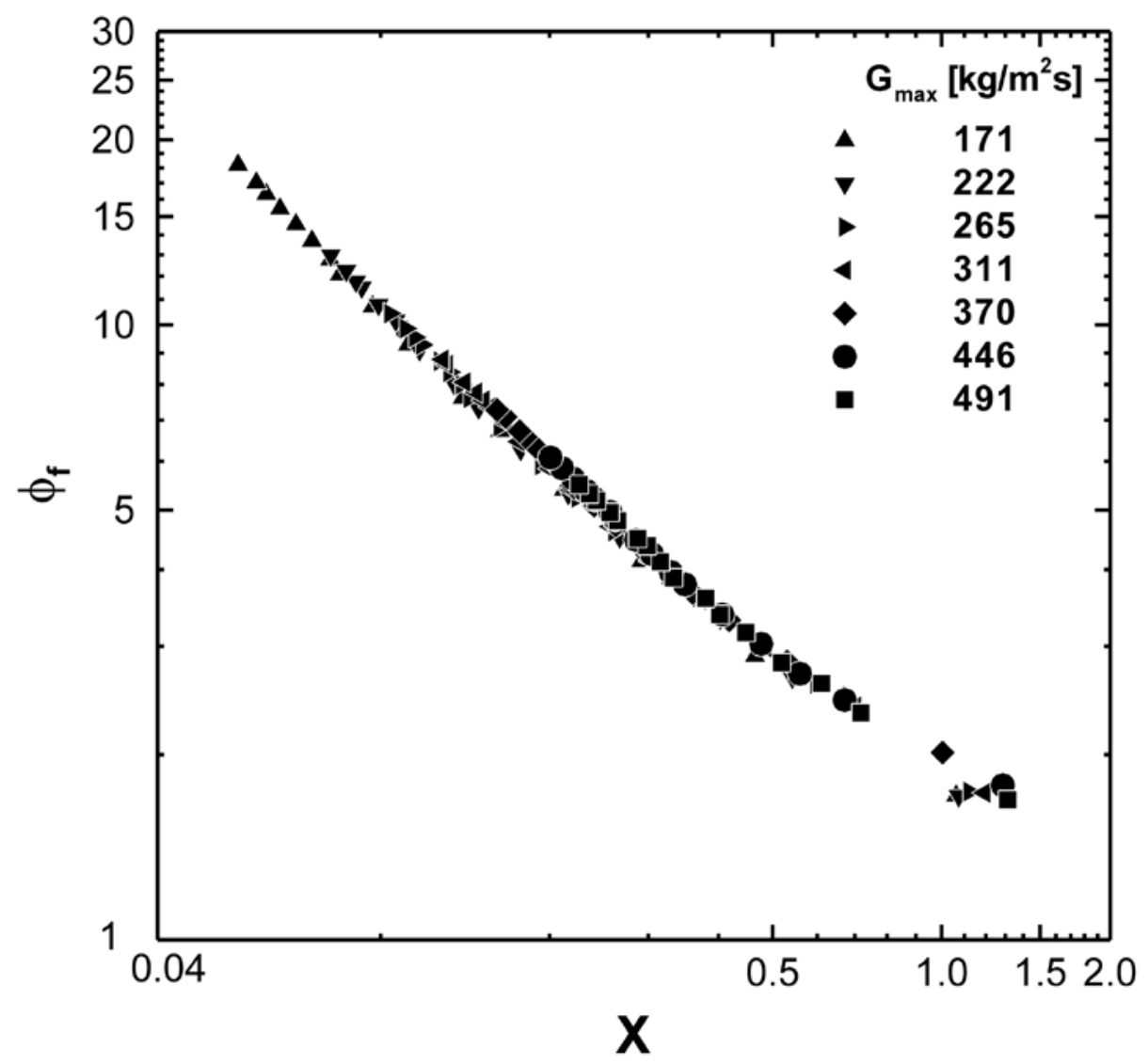

Figure 4 


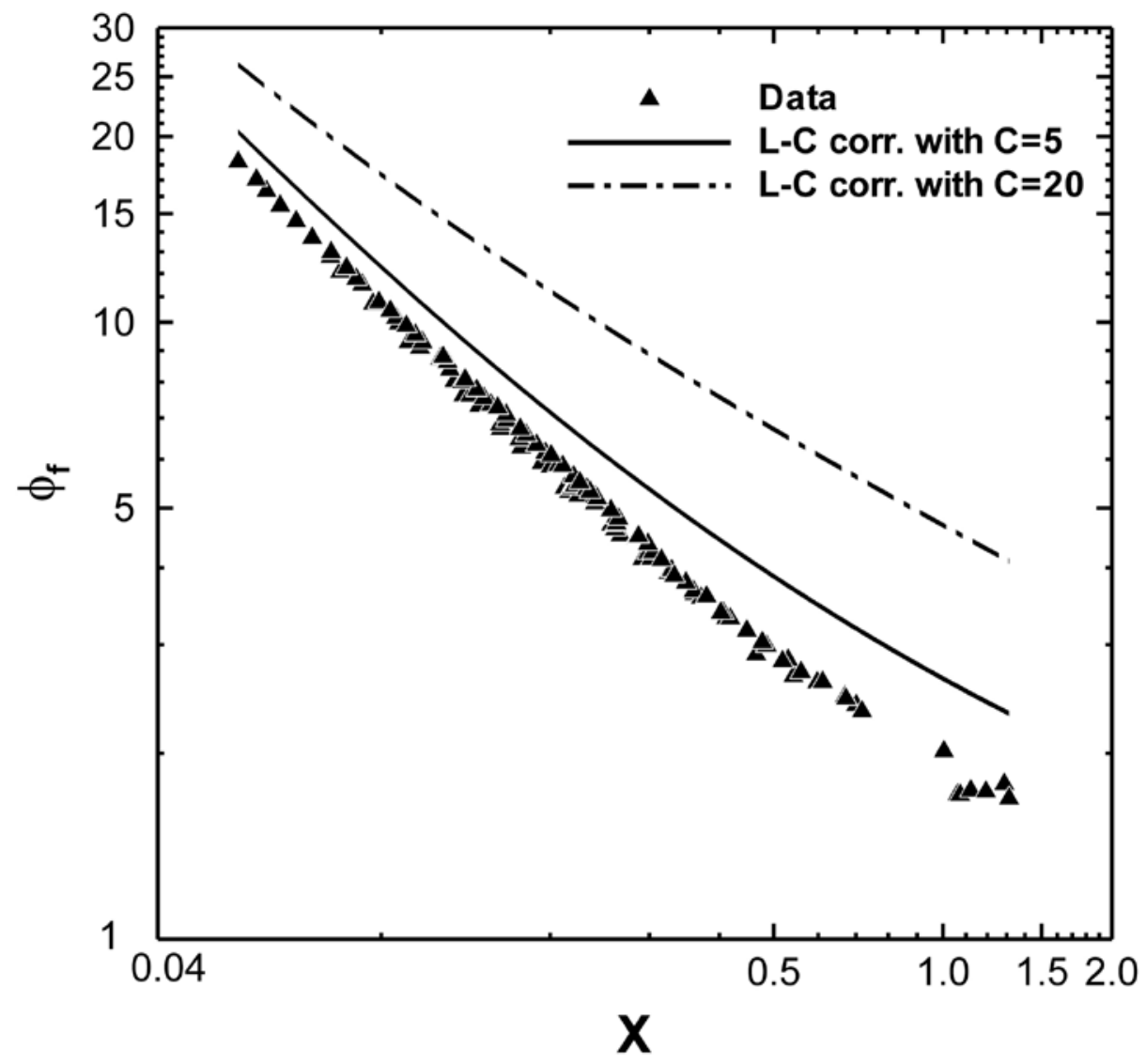

Figure 5 


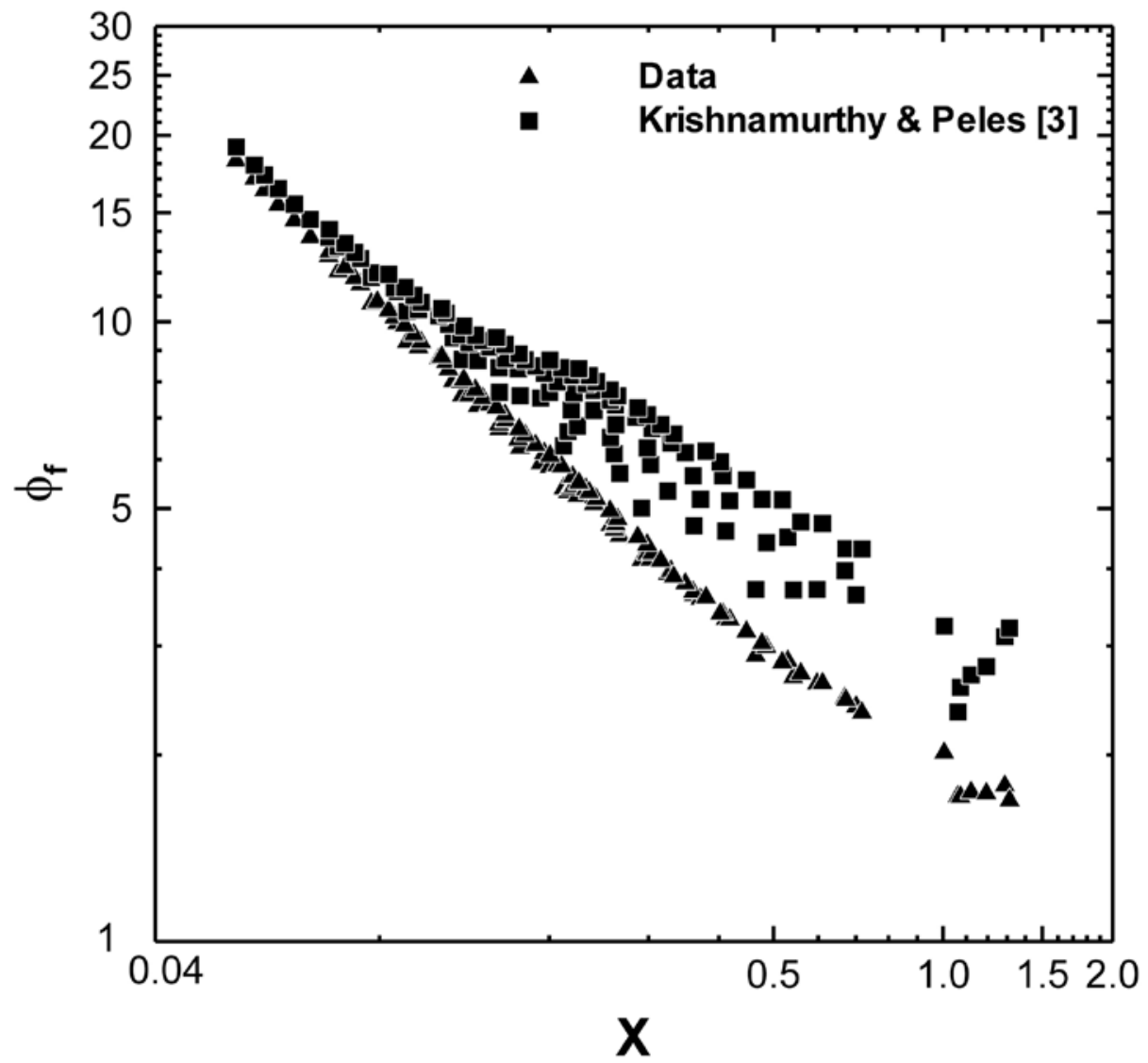

Figure 6 


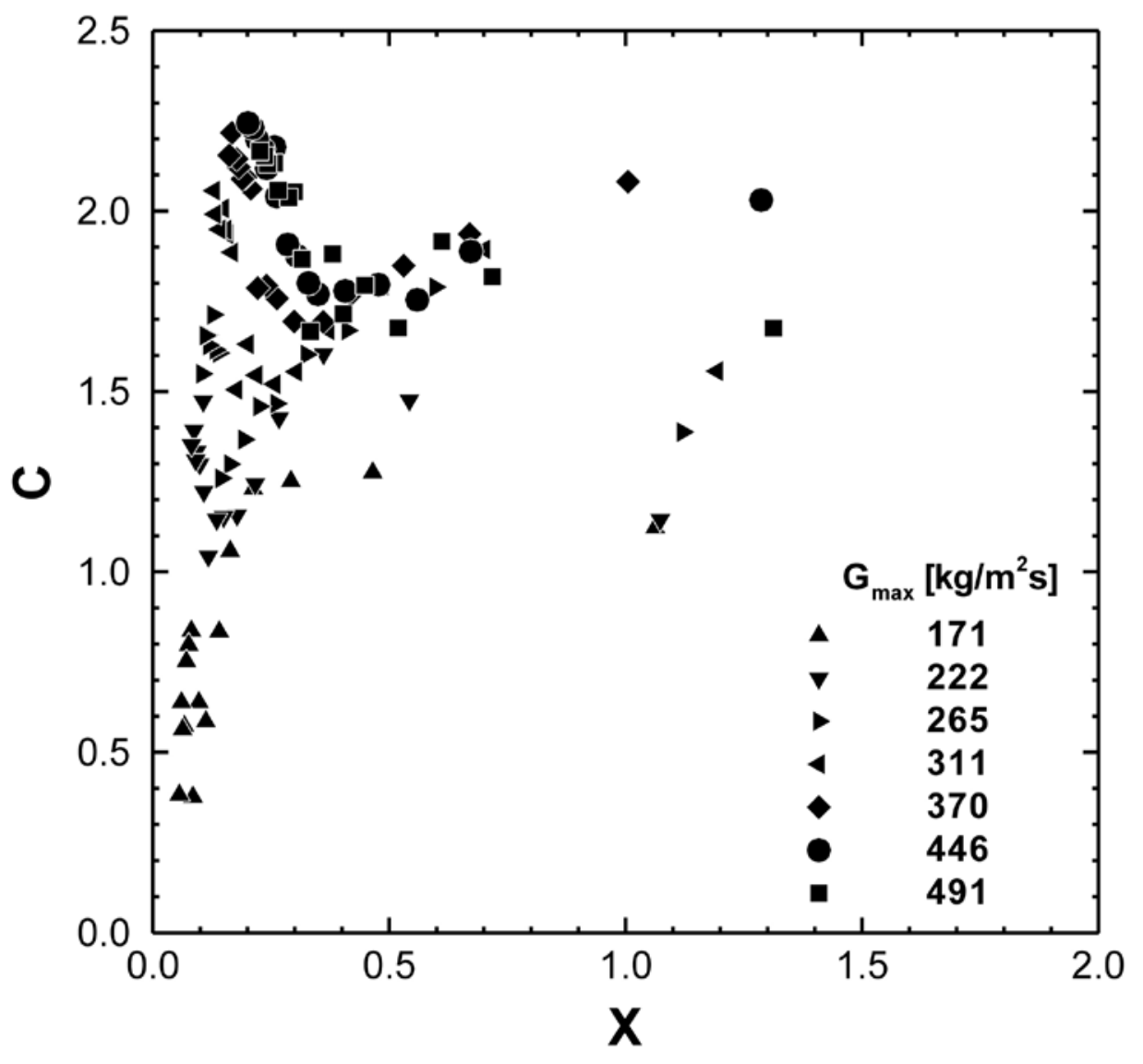

Figure 7 


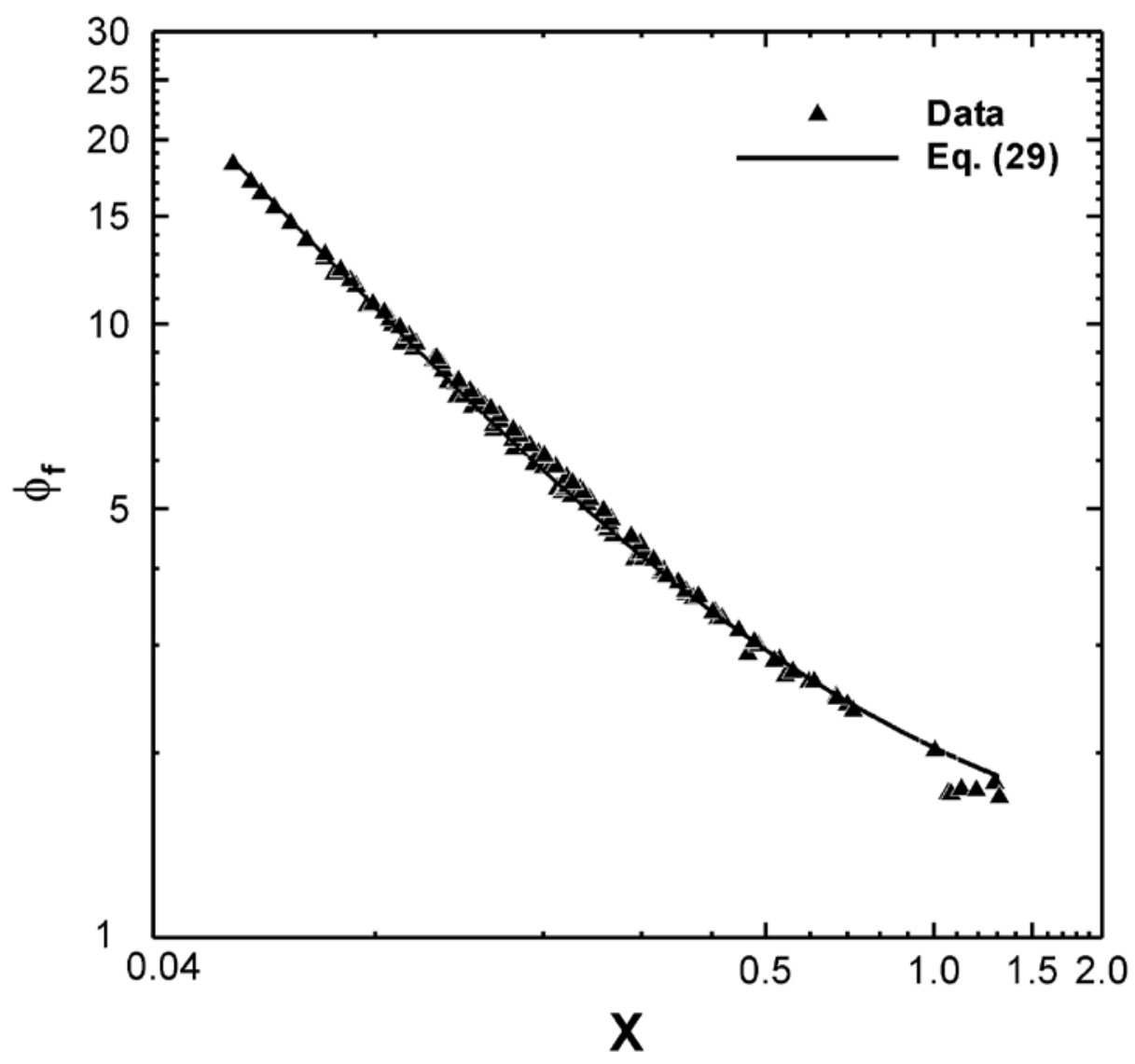

Figure 8 


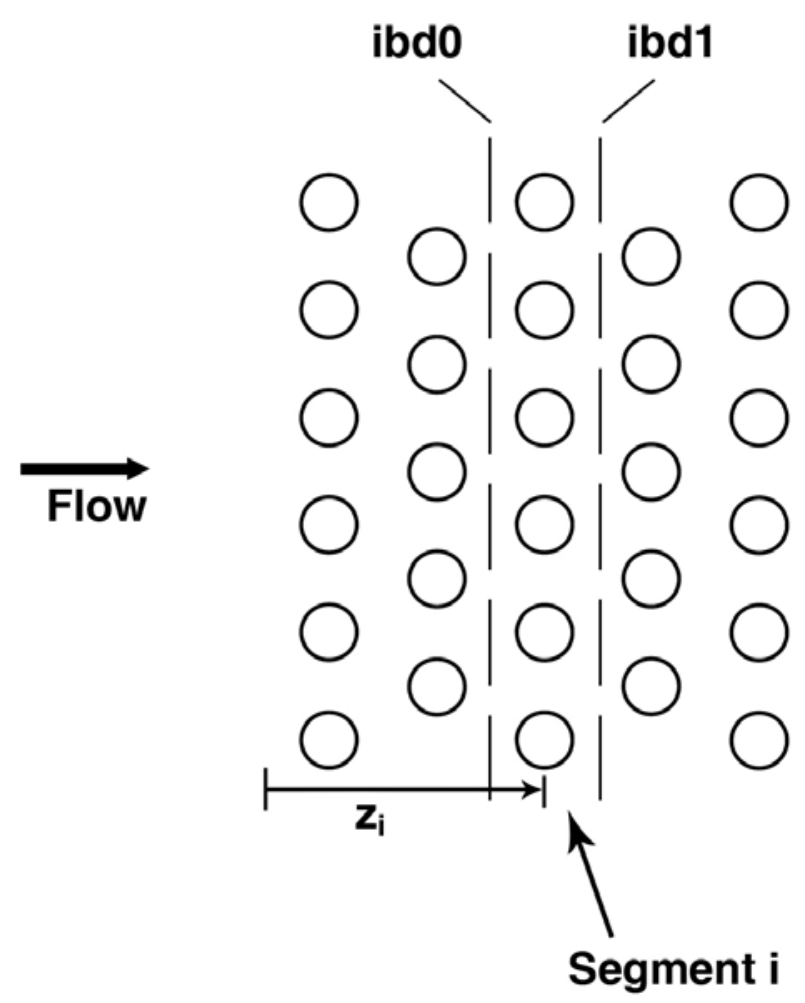

Figure 9 


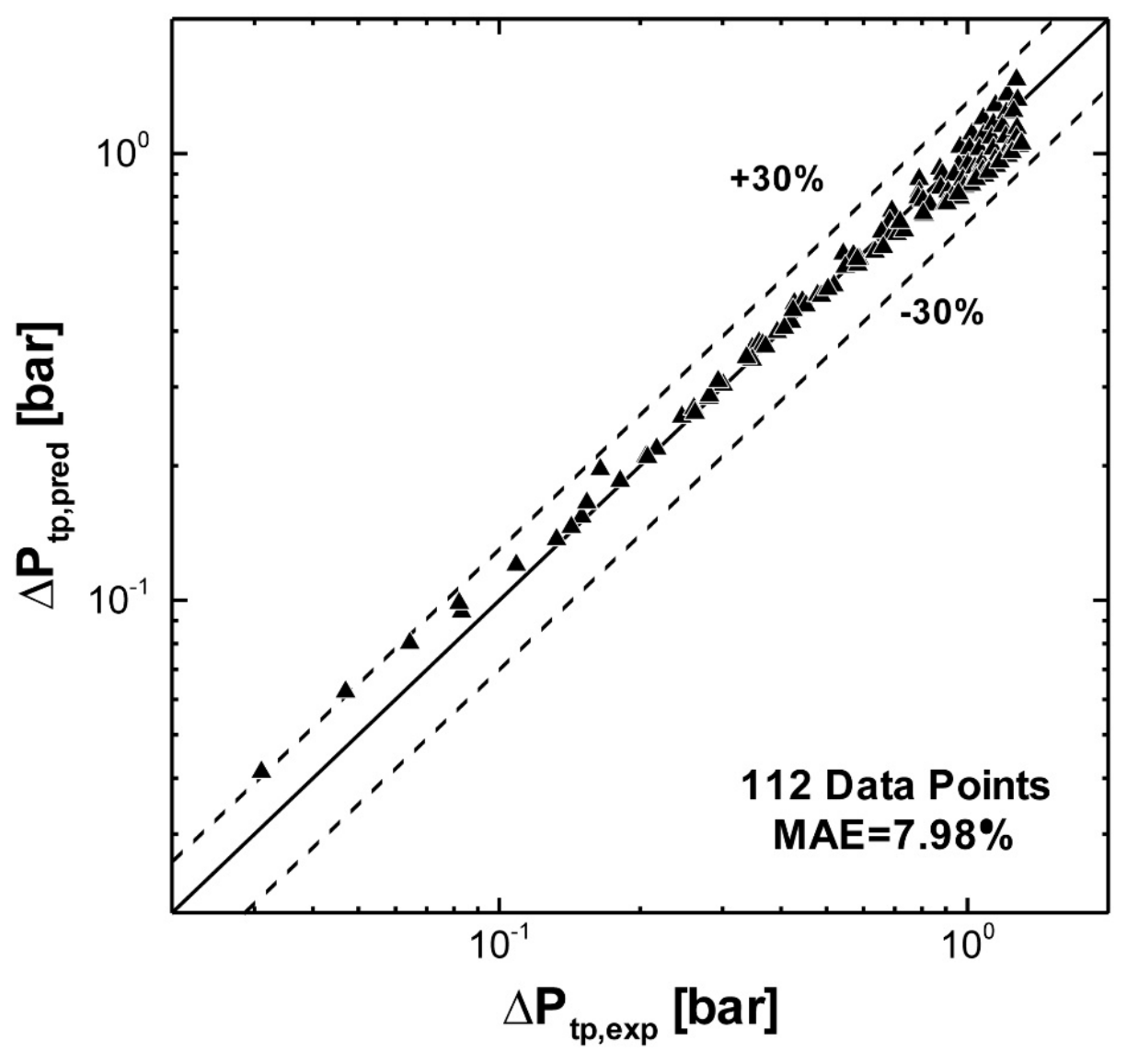

Figure 10 


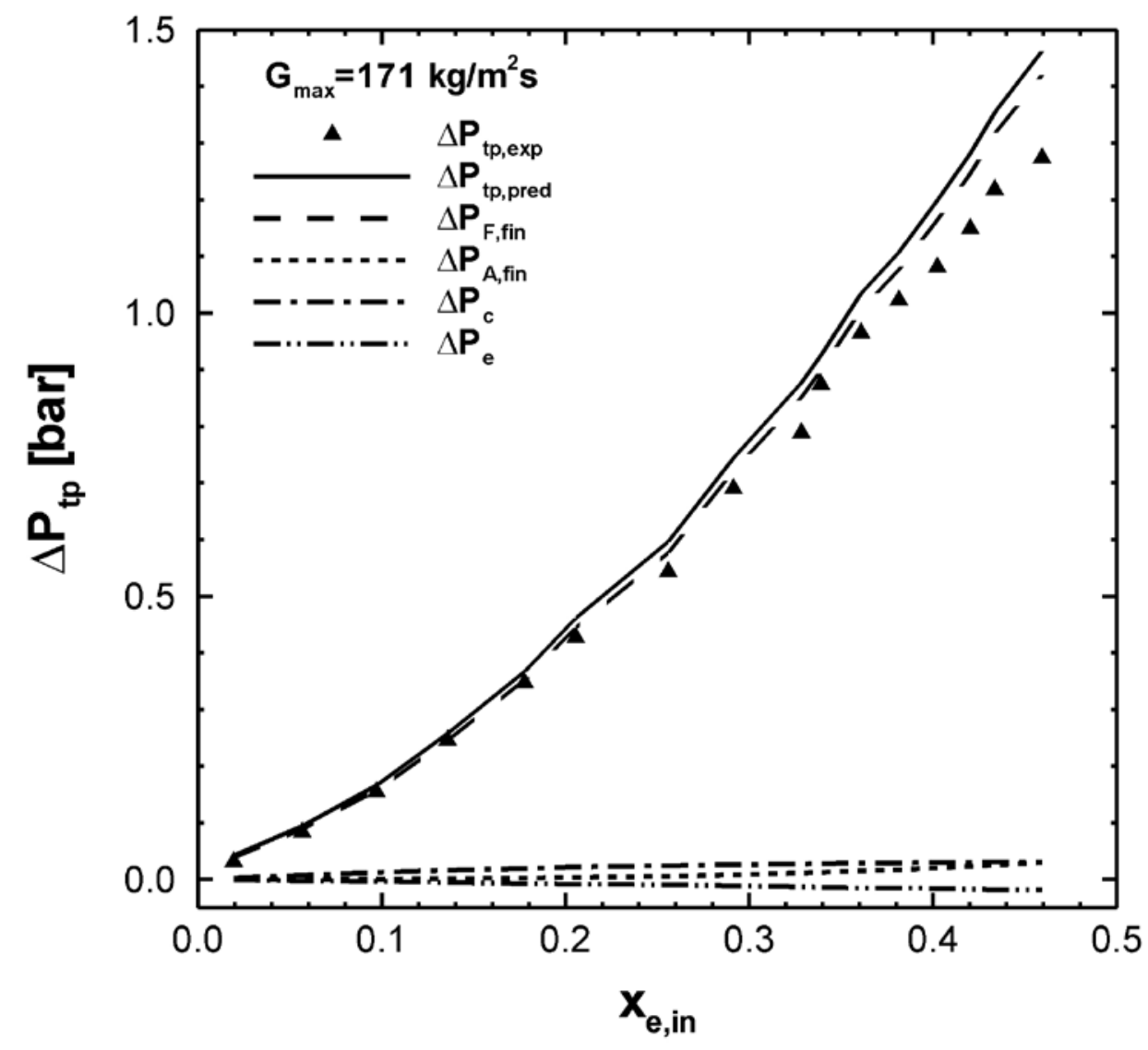

Figure 11 